\title{
Design and Analysis of a Wideband Microstrip Antenna for High Speed WLAN
}

\author{
S M Masudur Rahman Al-Arif \\ Islamic University of Technology \\ Gazipur, Dhaka \\ Bangladesh - 1704
}

\author{
Md. Fokhrul Islam, Ph.D \\ Islamic University of Technology \\ Gazipur, Dhaka \\ Bangladesh - 1704
}

\begin{abstract}
Allocation of frequency spectrum for Wireless LAN is different in different countries. This presents a myriad of exciting opportunities and challenges for design in the communications arena, including antenna design. The high speed WLAN has many standards and most antennas available do not cover all the standards. The primary goal of this work is to design antenna with smallest possible size and better polarization that covers all the high speed WLAN standards ranging from $4.90 \mathrm{GHz}$ to $5.82 \mathrm{GHz}$.
\end{abstract}

\section{General Terms}

Antenna design, WLAN, Microstrip.

\section{Keywords}

Antenna design, WLAN, Microstrip.

\section{INTRODUCTION}

WLANs are used worldwide and at different region of world different frequency bands are used. The WLAN standard IEEE 802.11 a operate in the $5-6 \mathrm{GHz}$ band, which provides reliable high-speed connectivity up to $54 \mathrm{Mbits} / \mathrm{s}$. But USA, Europe and some other countries use different frequency bands for this high speed 802.11a standard.

Among the two popular bands used for IEEE 802.11a standard; USA uses 5.15-5.35 GHz band and Europe uses $5.725-5.825 \mathrm{GHz}$ band. Some countries allow the operation in the $5.47-5.825 \mathrm{GHz}$ band. Another new band of $4.9-5.1 \mathrm{GHz}$ has been proposed for WLAN system as IEEE $802.11 \mathrm{j}$ in Japan [1]. Most of the current antennas available at the moment supports only one or at max two of those standards.

Users have to use different transceivers for different region because of this variety of frequency band unless we can design an antenna that can cover the whole high speed WLAN range of $4.9-5.825 \mathrm{GHz}$. Our main objective in this work is to find a suitable antenna that can do so.

Different kind antennas and their suitability in the WLAN applications have been studied throughout the literature review. Based on literature review, a coaxial probe fed, single stacked, E - shaped microstrip patch antenna has been chosen over other antenna types. Then an exhaustive parametric study has been performed on the antenna in order to optimize the antenna for the mentioned wide bandwidth. An antenna with a bandwidth of $925 \mathrm{MHz}$ starting from $4.890 \mathrm{GHz}$ to 5.825 $\mathrm{GHz}$ and size of $26 \times 19 \mathrm{~mm}^{2}$ is found which is much smaller than other available antennas. Simulations for current distribution and radiation patterns have been examined at different frequencies inside that bandwidth to observe the antennas behavior on the whole frequency band. Then a brief comparison with other available antenna with the proposed antenna is described along with a summary of the parametric study. Finally scopes for future works are mentioned in conclusion.

\section{LITERATURE REVIEW}

Microstrip patch antenna has a lot of advantages but it also has the drawback of narrow bandwidth. Many researchers have been working to increase the bandwidth of microstrip antenna. It has been observed that the bandwidth of microstrip antenna may be increased by using air substrate [1], increasing the substrate thickness, introducing parasitic patches element either in co-planar or stack configuration. In [2], an aperture-coupled microstrip antenna is described with parasitic patches stacked on the top of the main patch. However, all these methods typically enlarge the antenna size, either in the antenna plane or in the antenna height. Another very popular way to increase bandwidth of single patch antenna is to modify the shape of a common radiator patch by cutting slots strategically in the metallic patch. This approach is particularly attractive because it can provide excellent bandwidth improvement and maintain a single-layer radiating structure to preserve the antenna's thin profile characteristic. The successful examples include U-slot patch antennas [3], Half Ushape antenna or L shape [4], V-slot patch antennas [5], double-C patch antennas [6] and E-shaped patch antennas [7-10].

Recently in a study [3], it was shown that a half U-slot patch antenna maintains similar wide-band behavior like the full Uslot patch. In [4] it was shown that modifying the U-slot to a truncated V-slot can improve the antenna bandwidth considerably. Double C path antennas have been used commercially since 1995 [6]. But among all the shapes, E shapes have gained most of the popularities because of its simplicity and robustness. When two parallel slots are incorporated into the antenna patch to form a $\mathrm{E}$ shape, the bandwidth increases significantly.

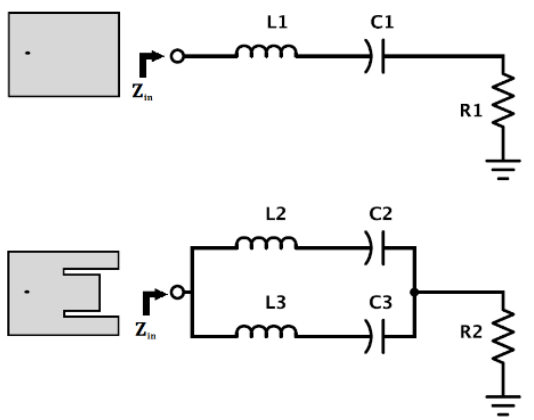

Fig 1: Simplified equivalent circuit of a rectangular patch and $E$ shape patch antenna. Resonant frequency of a rectangular patch antenna is determined by $\mathrm{L1C1}$ where in $\mathbf{E}$ shape increase of bandwidth achieved by having two resonant frequency determined by $\mathrm{L2C} 2$ and $\mathrm{L} 3 \mathrm{C} 3$. 
An E shaped patch antenna is designed in [8] to cover frequency band of $2.34-2.57 \mathrm{GHz}$ having a size of $76 \times 45$ $\mathrm{mm}^{2}$. The antenna is a modified form of the conventional Eshaped patch. They introduced asymmetry to design a circularly polarized E-shaped patch was developed.

In [5] researchers designed another E shaped microstrip patch antenna for IEEE $802.11 \mathrm{~b}$ standard. The wide-band mechanism of this antenna is explored by investigating the behavior of the currents on the patch. The slot length, width, and position are optimized to achieve a wide bandwidth. Finally, E-shaped patch antenna, resonating at wireless communication frequencies of 1.9 and $2.4 \mathrm{GHz}$, is designed. This antenna dimension was in scale of $70 \times 50 \mathrm{~mm}^{2}$.

In 2008 M A Matin and M A Mohd Ali demonstrated a low cost, compact stacked E-shaped patch antenna. The simulation results of its performance are investigated and the return loss is found under $-10 \mathrm{~dB}$ for the band $3.1-4.9 \mathrm{GHz}$, which is better than the square patch stacked E-shape patch antenna. The dimension and position of the rectangular patch as well as the shift of coaxial probe location have been optimized to achieve this wide bandwidth and it can be used for UWB lower band applications. This antenna has double substrate layer resulting a total height of $11.6 \mathrm{~mm}$. Size of the antenna is $37.4 \times 31.7 \mathrm{~mm}^{2}$ [11].

Another patch antenna with a slot and a tuning stub, or called a Modified E shaped Patch (ESP), has been studied in [7]. Simulation has shown that the tuning stub has introduced a new resonant frequency, resulting in a bandwidth of $380 \mathrm{MHz}$ $(5.3-5.75 \mathrm{GHz})$ with a central frequency of $5.58 \mathrm{GHz}$ while the bandwidth of a common rectangular patch of the same size on the same substrate is $220 \mathrm{MHz}$ by simulation and $254 \mathrm{MHz}$ by experiment.

In [6] a very good antenna having a size of $33.2 \times 22.2 \mathrm{~mm}^{2}$ is described. Theoretical analyses and preliminary experiments indicate that these antennas have a return loss $>10 \mathrm{~dB}$ in the two IEEE 802.lla wireless bands, namely $5.15-5.35 \mathrm{GHz}$ and 5.725-5.825 GHz. This antenna can cover USA and European standard of WLAN, where this thesis targets a higher frequency band that covers all the standards in between 4.9 $\mathrm{GHz}$ to $5.825 \mathrm{GHz}$.

Another antenna coving two different bands resonating at 5.3 $\mathrm{GHz}$ and $7.4 \mathrm{GHz}$ is designed in [12] with impedance bandwidth of $760.43 \mathrm{MHz}$ and $1.39 \mathrm{GHz}$ respectively. Slots in the ground plane and multiple element arrays are used to achieve better bandwidth. The antenna can be used for high speed (IEEE 802.11a) wireless computer local area network (WLAN) and other wireless application.

\section{METHODOLOGY}

\subsection{Specifications}

Our objective is to design an antenna that can serve all the hispeed WLAN standards available throughout the world in the 5-6 GHz ranges. More specifically our antenna should support:

\section{- $\quad$ 802.11a (USA) or 5.15-5.35 GHz band; \\ - $\quad$ European 802.11a or 5.725-5.825 GHz band \\ - $\quad$ Middle-eastern WLAN or 5.47-5.825 GHz band; \\ - Newly approved IEEE $802.11 \mathrm{j}$ or $4.9-5.1 \mathrm{GHz}$ \\ band;}

The proposed design should provide at least $-10 \mathrm{~dB}$ return loss for the total band of 4.90-5.825 GHz. The bandwidth of the antenna can be said to be those range of frequencies over which the RL is less than $-9.5 \mathrm{~dB}(-9.5 \mathrm{~dB}$ corresponds to a
VSWR of 2 which is an acceptable figure). In this work -10 $\mathrm{dB}$ return loss is taken as standard. Recent works on the $\mathrm{E}$ shaped patch antenna shows that antenna dimensions for 5-6 $\mathrm{GHz}$ band was limited by $33.2 \times 22.2 \mathrm{~mm}^{2}$. The optimized antenna should have smaller dimensions.

Expression for resonance frequency of an E-shaped microstrip antenna has been found in [13]. Here the resonance frequencies are calculated by equating its area to an equivalent area of a rectangular microstrip patch antenna. This expression of resonance frequencies showed a good agreement with measured result. Here in this work those expressions are used to find out different dimensions of the $\mathrm{E}$ shape patch antenna for lower resonance frequency of 4.95 $\mathrm{GHz}$ and higher resonance frequency of $5.77 \mathrm{GHz}$. Substrate dielectric constant is chosen as 2.2 and height as $5 \mathrm{~mm}$.

Parameters found from the calculation are: $\mathrm{W}=33.89 \mathrm{~mm}, \mathrm{~L}$ $=18.69 \mathrm{~mm}, \mathrm{~W} 1=10.45 \mathrm{~mm}, \mathrm{~W} 2=8.87 \mathrm{~mm}, \mathrm{~L} 1=12.66$ $\mathrm{mm}$ and $\mathrm{Ls}=13.81 \mathrm{~mm}$. As a starting reference we are going to use these parameters to design a simplest form of the $\mathrm{E}$ shape antenna.
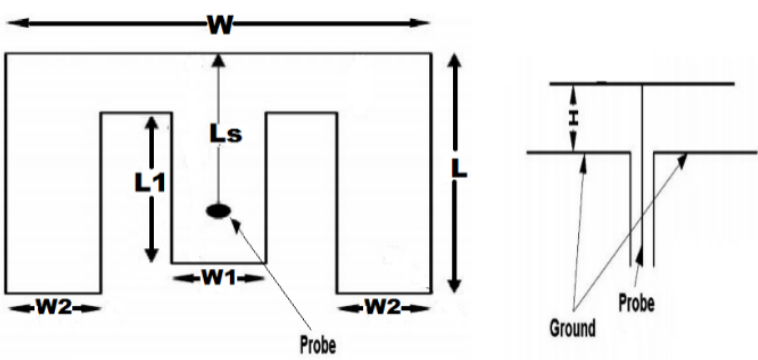

Fig 2: Schematic of antenna \& different dimensions

\subsection{Optimization}

Optimization is done by changing several parameters to find out the most suitable antenna for our particular operation. To observe the resonance condition, return loss S11 parameter is taken into account. After finding out the parameters which can produce an acceptable return loss response for $4.9-5.82 \mathrm{GHz}$ range, we proceed to observe radiation pattern and current distribution of the found antenna at different operating frequency.

As stated earlier antenna dimensions have been found using closed form expressions from [13]. To keep the initial design simple the parameters are rounded up to the nearest integers. So the antenna dimensions are $\mathrm{W}=34 \mathrm{~mm}, \mathrm{~L}=19 \mathrm{~mm}, \mathrm{~W} 1=$ $10 \mathrm{~mm}, \mathrm{~W} 2=9 \mathrm{~mm}, \mathrm{~L} 1=13 \mathrm{~mm}$ and $\mathrm{Ls}=13.8 \mathrm{~mm}$ Substrate Dielectric Constant, $\varepsilon r=2.2$ and $\mathrm{H}=5 \mathrm{~mm}$. Now a single antenna with these dimensions is designed and simulated using IE3D.

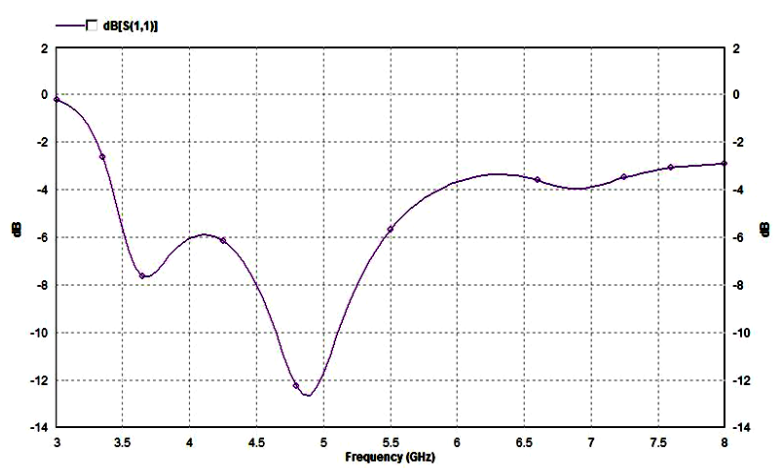

Fig 3: Return loss of the initial antenna 

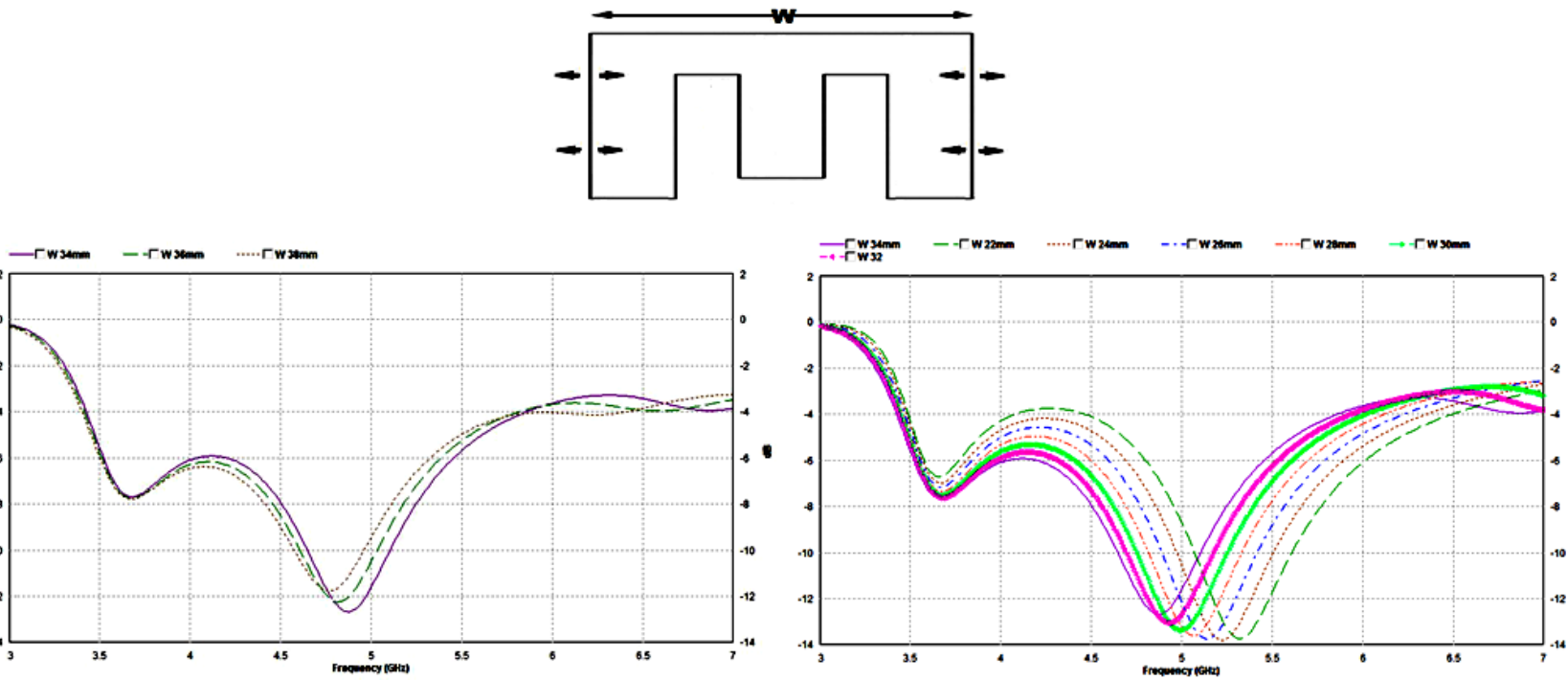

Fig 4: Effect of parameter W

Return loss of the designed antenna shows us a resonant condition at $4.9 \mathrm{GHz}$ (Fig 3). This is due to the anomaly in the expressions used in the calculation. Those expressions were optimized for E shape patch antenna for lower frequency band of 2-3 GHz band. Although resonance frequency of this antenna is not in the desired range, but it is used for further analysis. An exhaustive parametric set of analysis are done in order to tune the antenna to the desired frequency band of 4.9 $\mathrm{GHz}$ to $5.82 \mathrm{GHz}$. The return loss is observed as the parameters W, L, L1, W1 and Ls are changed. First width, W, is changed to higher value and lower value (Fig. 4). As W is increased from $34 \mathrm{~mm}$, the resonant frequency shifting to its left and the return loss is also degrading. Both them are unwanted scenarios (see fig4). So now we should decrease W from 34 so that resonant frequency shifts to its right until return loss reaches its lowest possible value. So from Figure $4 \mathrm{~b}$ we can see as we were decreasing the value of $\mathrm{W}$, the RL improves until $\mathrm{W}=26 \mathrm{~mm}$. For $\mathrm{W}=26 \mathrm{~mm}, 24 \mathrm{~mm} \mathrm{RL}$ are almost equal, whereas at $\mathrm{W}=22 \mathrm{~mm}$ it starts increasing which is unwanted. Again at $\mathrm{W}=26 \mathrm{~mm},-10 \mathrm{~dB}$ return loss covers 4.89-5.416 GHz where for $\mathrm{W}=24 \mathrm{~mm},-10 \mathrm{~dB} \mathrm{RL}$ crosses our lower limit of $4.9 \mathrm{GHz}$. So $\mathrm{W}$ is fixed at $26 \mathrm{~mm}$ for further study. This process is repeated with other dimensions: W1, L, L1, W2 and Ls. Changing directions are given in Fig 5 with corresponding return losses in Fig 6.

In original antenna $\mathrm{W} 1=10 \mathrm{~mm}$. Figure $6 \mathrm{a}$ shows the frequency response for $\mathrm{W} 1=12 \mathrm{~mm}$. Increased $\mathrm{W} 1$ is degrading our frequency response. Now, W1 is decreased to observe the effect. Figure $6 \mathrm{~b}$ shows the frequency response of the antenna for $\mathrm{W} 1=10 \mathrm{~mm}, 8 \mathrm{~mm}, 6 \mathrm{~mm}, 5 \mathrm{~mm}$ and $4 \mathrm{~mm}$. Decreasing W1 from $10 \mathrm{~mm}$ to $4 \mathrm{~mm}$ widens the bandwidth more and more, but at $\mathrm{W} 1=4 \mathrm{~mm}$ the response curve moves far right than our desired band. So $\mathrm{W} 1=5 \mathrm{~mm}$ provides the best return loss of $-44 \mathrm{~dB}$ at $5.54 \mathrm{GHz}$ with higher than $-10 \mathrm{~dB}$ return loss for frequency range of 5.12-6.01 GHz.

Now, keeping $\mathrm{W} 1$ at $5 \mathrm{~mm}, \mathrm{~L}$ is now increased and decreased by $1 \mathrm{~mm}$ from top (Fig 5c). Fig 6c shows that increasing $\mathrm{L}$ from top moves the return loss curves leftwards and decreasing L moves the curves in opposite direction. Similarly changing $\mathrm{L}$ from bottom (Fig 5d) also degrades the return loss (Fig 6d) abruptly. So, $\mathrm{L}$ is kept as $19 \mathrm{~mm}$.

Then we move on to L1 (Fig 5e). In Figure 6e, we see changing $\mathrm{L} 1$ from 13 to 12 increases the return loss and moves the resonant frequency to the right. While increasing L1 from 13 to 14 keeps the RL almost same but moves the resonant frequency to left. At L1 = 14 the frequency range having greater than $-10 \mathrm{~dB}$ return loss becomes $4.88-5.811$ $\mathrm{GHz}$ which almost covers the desired band. $\mathrm{L} 1=14 \mathrm{~mm}$ is now set.

Next parameter to investigate is W2 (see Fig 5f). W2 is changed from $9 \mathrm{~mm}$ to $8 \mathrm{~mm}$ and $10 \mathrm{~mm}$ to observe the effect

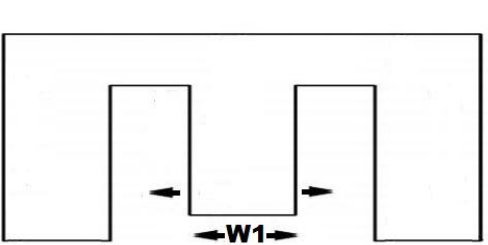

(a)

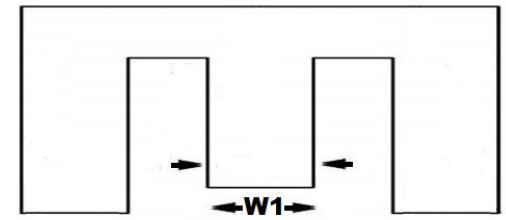

(b)

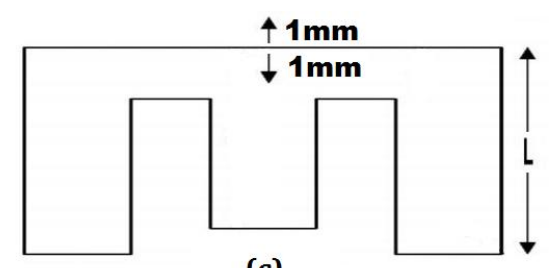

(c)

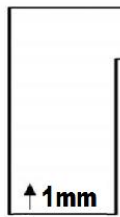

$\downarrow 1 \mathrm{~mm}$

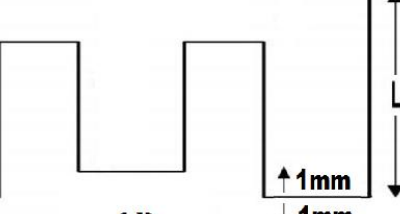

(d)

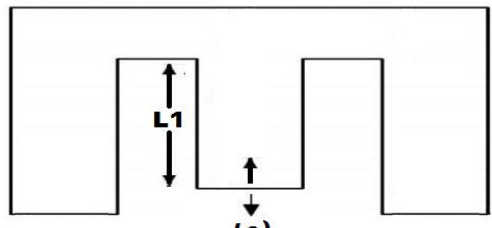

(e)

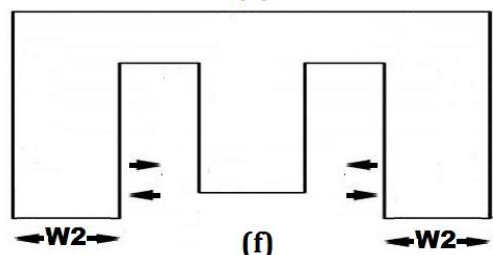

Fig 5: Parameter changing directions a) Increasing W1 b) Decreasing W1 c) L from top d) L from bottom e) L1 f) W2 


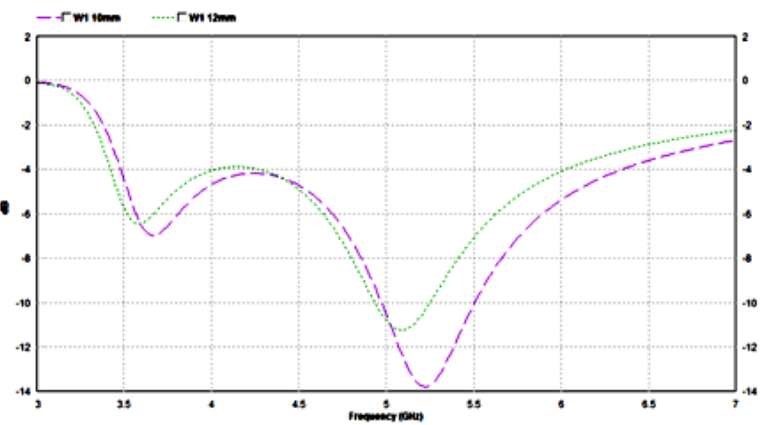

(a)

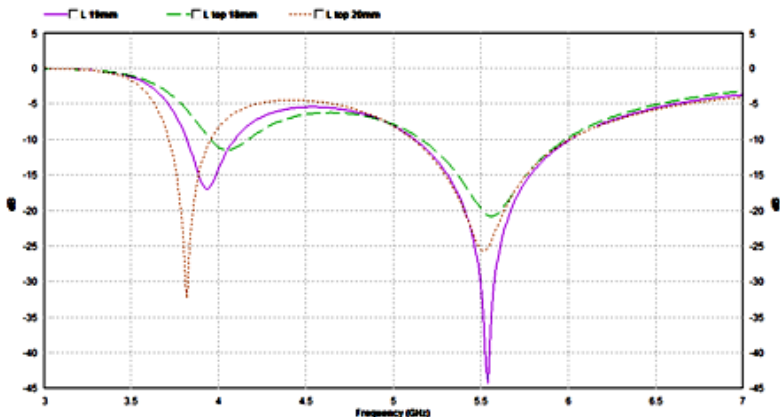

(c)

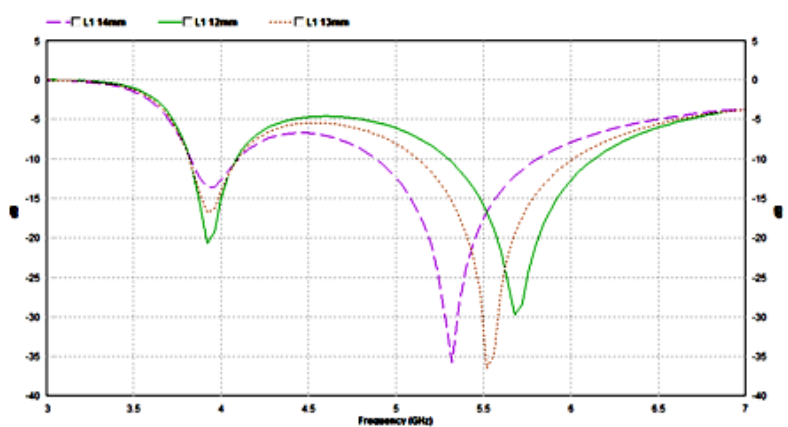

(e)

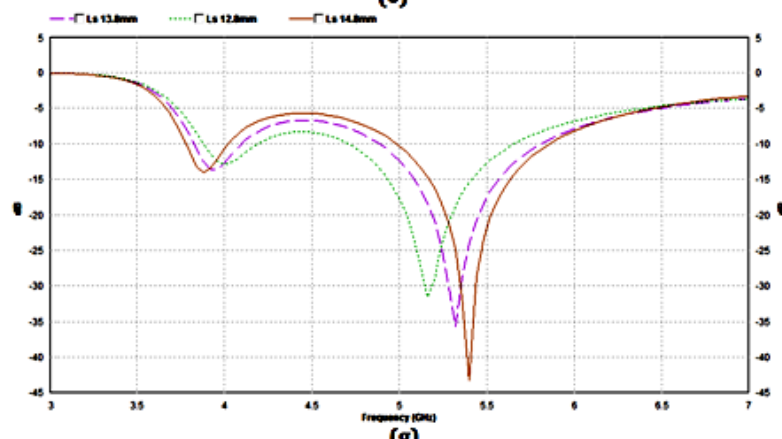

(g)

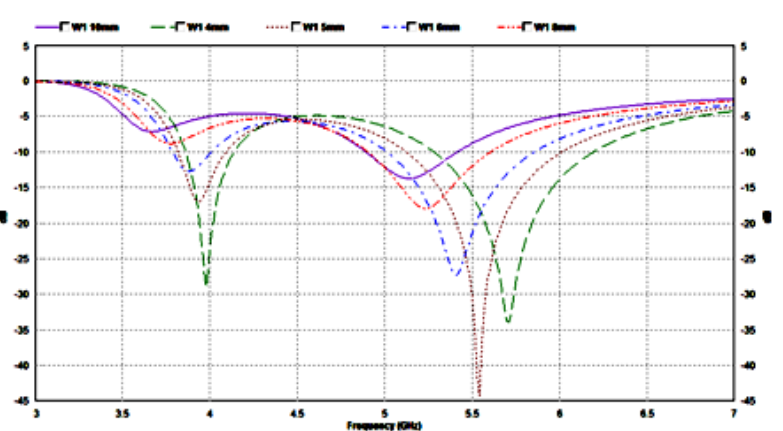

(b)

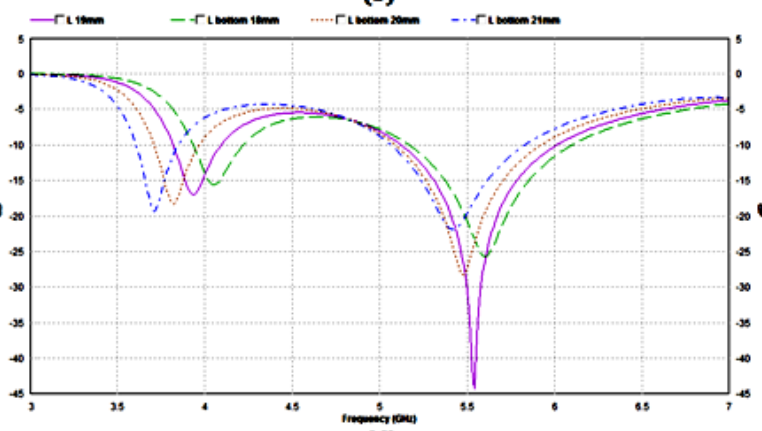

(d)
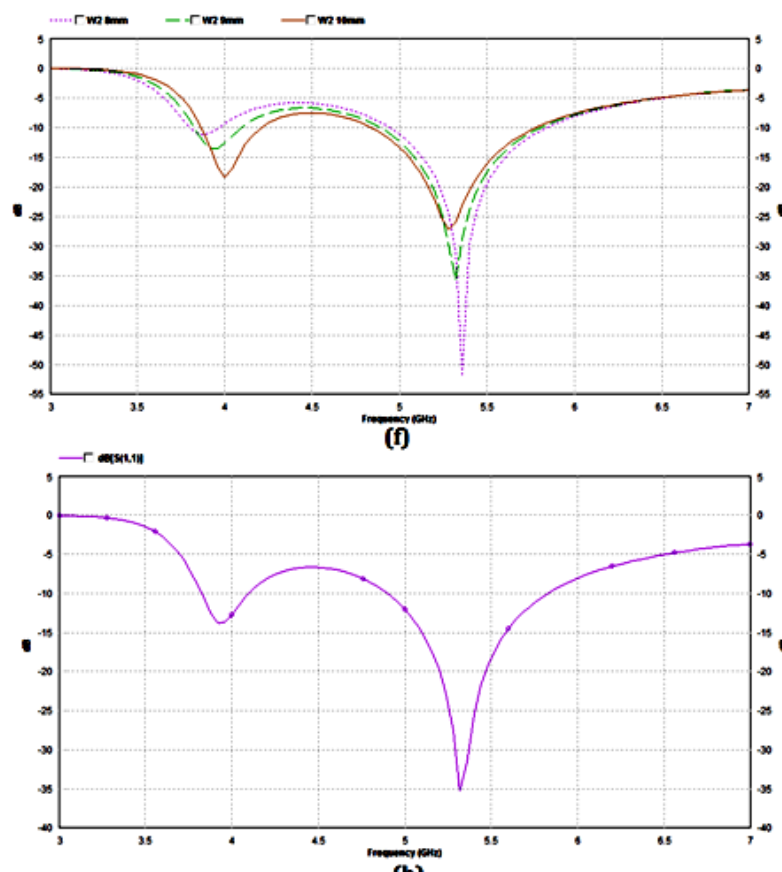

(h)

Fig 6: Return loss a) Increasing W1 b) Decreasing W1 c) L from top d) L from bottom e) L1 f) W2 g) Ls h) Final return loss

on return loss and bandwidth (Fig 6f). Increasing W2 moves the response leftwards and degrades the return loss whereas decreasing W2 moves the response rightward and improves the return loss. But although return loss is lower we cannot take it because the lower $-10 \mathrm{~dB}$ frequency crossing our threshold of $4.9 \mathrm{GHz}$. So W2 $=9 \mathrm{~mm}$ is the best option.

Ls is last parameter to study (Fig 2). Ls is change from 13.8 $\mathrm{mm}$ to $12.8 \mathrm{~mm}$ and $14.8 \mathrm{~mm}$. Comparison between their return loss vs frequency curve is shown in Fig $6 \mathrm{~g}$. Changing Ls is changing the resonant frequency which is worse than the situation at $\mathrm{L} 1=14 \mathrm{~mm}$ of Fig $6 \mathrm{e}$. Any change in resonant frequency moves the whole coverage bandwidth with it.
To fine tune the frequencies many points between $\mathrm{L} 1=14$ $\mathrm{mm}$ and $\mathrm{L} 1=13.8 \mathrm{~mm}$ were simulated. And finally for $\mathrm{L} 1=$ $13.94 \mathrm{~mm}$ a frequency response was found where the whole range from $4.8966 \mathrm{GHz}$ to $5.8258 \mathrm{GHz}$ achieved more than $10 \mathrm{~dB}$ amplification (Fig 6h). So our desired criterion is achieved. And final antenna dimension is $\mathrm{W}=26 \mathrm{~mm}, \mathrm{~L}=19$ $\mathrm{mm}, \mathrm{W} 1=5 \mathrm{~mm}, \mathrm{~W} 2=9 \mathrm{~mm}, \mathrm{~L} 1=13.94 \mathrm{~mm}$ and $\mathrm{Ls}=13.8$ $\mathrm{mm}$.

\section{RESULTS}

In the previous section an intensive set of experiments has been done to optimize the antenna for the frequency range of 4.9-5.825 GHz. As a result we have found an antenna having an area of $26 \times 19 \mathrm{~mm}^{2}$ with lower than $-10 \mathrm{~dB}$ return loss for a 
frequency band of $4.8966 \mathrm{GHz}$ to $5.8258 \mathrm{GHz}$. Another additional band ranging from $3.8 \mathrm{GHz}$ to $4.1 \mathrm{GHz}$ has also been found under $-10 \mathrm{~dB}$ return loss which can be very useful for smart devices that use GPS signals from $\mathrm{C}$ band satellites. The antenna size is smaller than any of the single substrate antenna found in the literature review for the IEEE 802.11a USA and European WLAN standards.

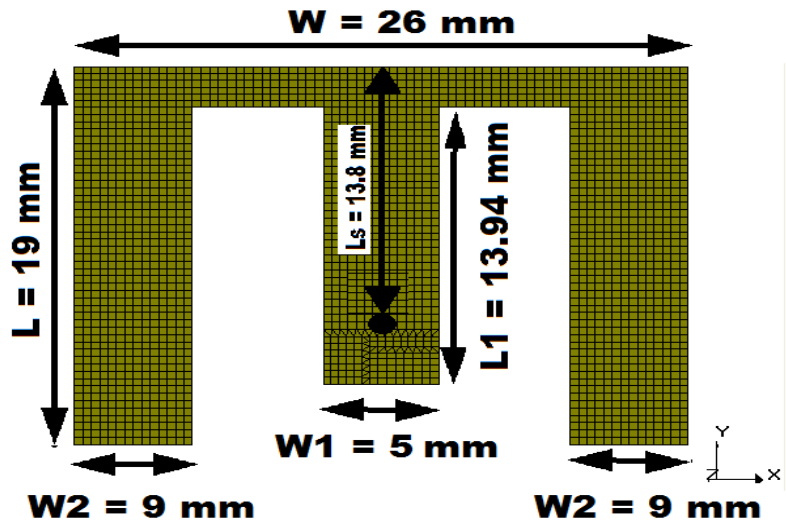

Fig 7: Proposed Antenna

The proposed antenna covers North American WLAN standard ranging from 5.15 to $5.35 \mathrm{GHz}$, European WLAN standard ranging from $5.725-5.825 \mathrm{GHz}$, Asian and Middleeastern WLAN 5.47-5.63 GHz and the newly approved Japanese WLAN standard ranging from 4.9 to $5 \mathrm{GHz}$ frequency bands; performance of the antenna should be examined for each of the standards. Performances are observed by simulating antennas average current distribution, vector current distribution, radiation patterns at the center frequencies $(5 \mathrm{GHz}, 5.25 \mathrm{GHz}, 5.5 \mathrm{GHz}$ and $5.775 \mathrm{GHz})$ of each band. The current distribution gives us an insight into the antenna structure by showing the density and the direction of current movement inside the patch at different frequencies. It also gives us how different part of the antenna behaves for different operating frequencies. Radiation pattern shows us how antenna radiates its output signal. It also provides information about the gain and polarization of E-H fields.
For all frequencies average current distribution (Fig 8) are mostly in green or in blue color corresponding to an amplification of from $-20 \mathrm{~dB}$ to $-40 \mathrm{~dB}$. Which means for all frequencies in the range of $4.9-5.825 \mathrm{GHz}$ our antenna can work smoothly as a transmitter or a receiver. The vector distributions of the current over the surface of patch are shown in figures 9 . In the lower frequencies we can observe the density is higher on the side wings where as in the higher frequencies density is high in the central arm and in the body. But for all frequencies, the distribution represents resonant condition which means even in terms of vector distribution our antenna works fine in the whole WLAN range. A good antenna should maintain its radiation pattern and polarization throughout the frequency range that it covers. Fig 10 shows $2 \mathrm{D}$ radiation pattern of all four different frequencies. The antenna provides a good radiation pattern and similar polarization for the entire band of 4.9 to $5.825 \mathrm{GHz}$.

\section{DISCUSSIONS}

Not much work has been done to design antenna that can operate satisfactorily over all the high speed WLAN standards. In [11], an antenna is designed for $3.1-4.9 \mathrm{GHz}$ range covering only a single American special purpose WLAN standard 802.11y where our antenna supports $802.11 \mathrm{a}, 802.11 \mathrm{n}, 802.11 \mathrm{ac}$ and $802.11 \mathrm{j}$ standards. Also our antenna provides a considerable reduction in antenna size and height from [11]. Another E shaped antenna is demonstrated with a bandwidth of $380 \mathrm{MHz}$ with a central frequency of $5.58 \mathrm{GHz}$ [7] where as our antenna provides a huge bandwidth of $925 \mathrm{MHz}$ with frequency band ranging from $4.90-5.825 \mathrm{GHz}$. An antenna to cover two 802.11a standards is designed in [6] with a size of $33.2 \times 22.2 \mathrm{~mm}^{2}$, where our proposed antenna covers all standards including these two and have a size of only $26 \times 19 \mathrm{~mm}^{2}$. So comparative study shows that proposed antenna provides better outputs in terms of bandwidths, coverage and dimensions than the available antennas.

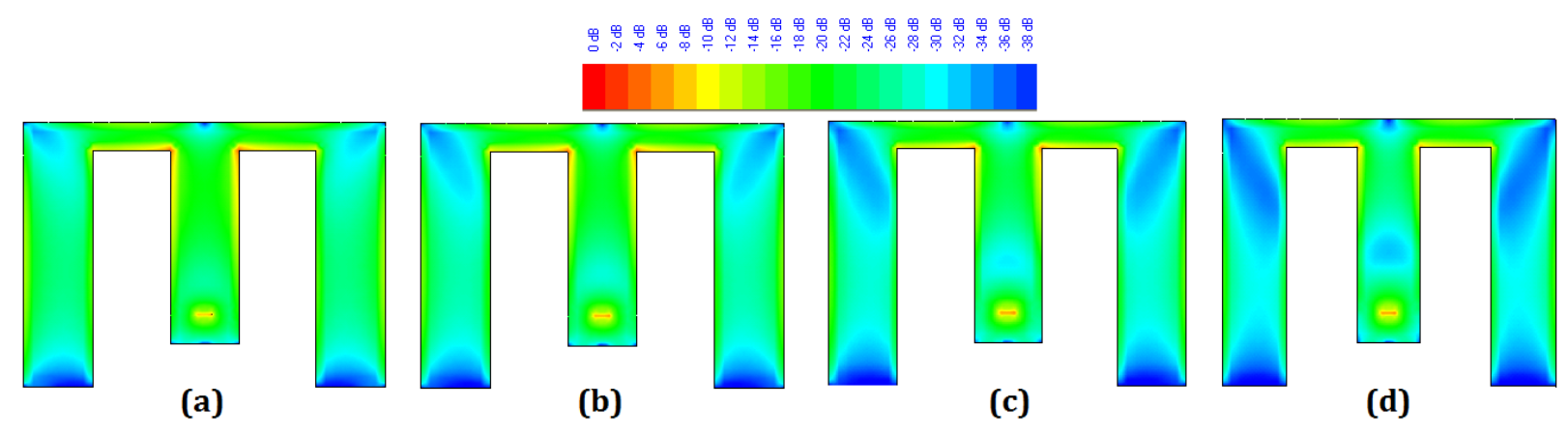

Fig 8: Average current distribution at a) $5 \mathrm{GHz}$, b) $5.25 \mathrm{GHz}$, c) $5.5 \mathrm{GHz}$ and d) $5.775 \mathrm{GHz}$

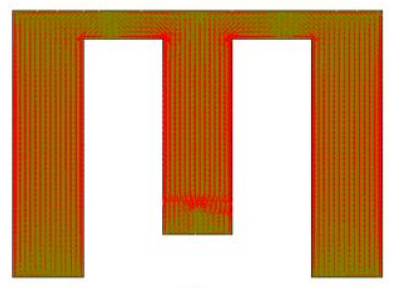

(a)

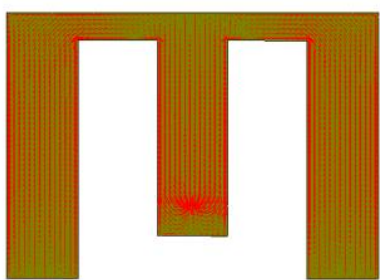

(b)

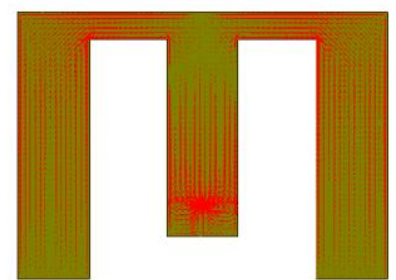

(c)

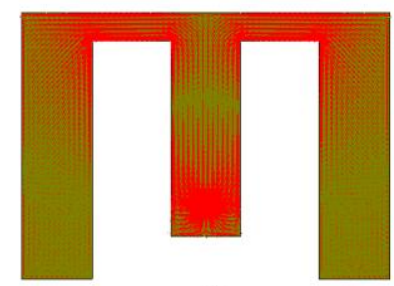

(d)

Fig 9: Vector current distribution at a) $5 \mathrm{GHz}$, b) $5.25 \mathrm{GHz}$, c) $5.5 \mathrm{GHz}$ and d) $5.775 \mathrm{GHz}$ 


\section{CONCLUSION}
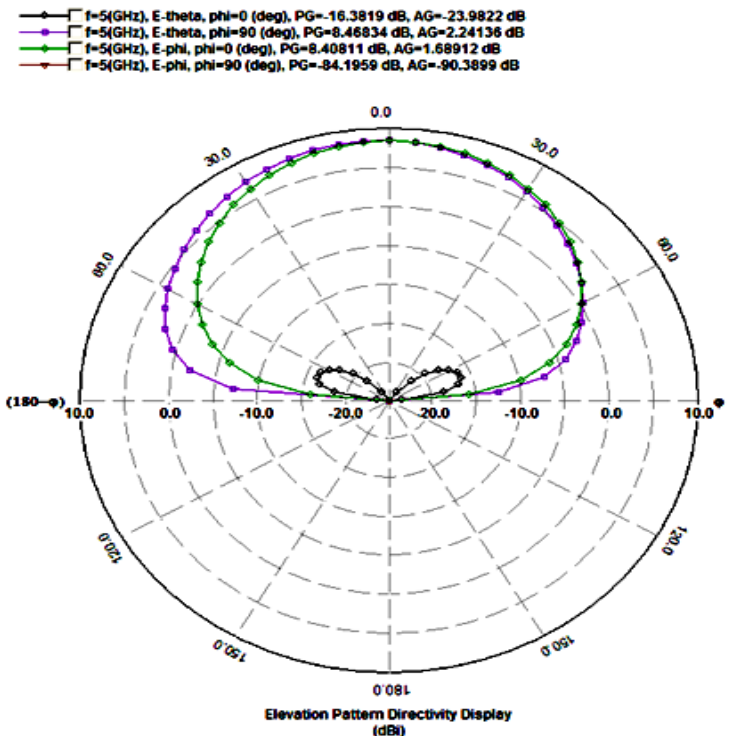

(a)

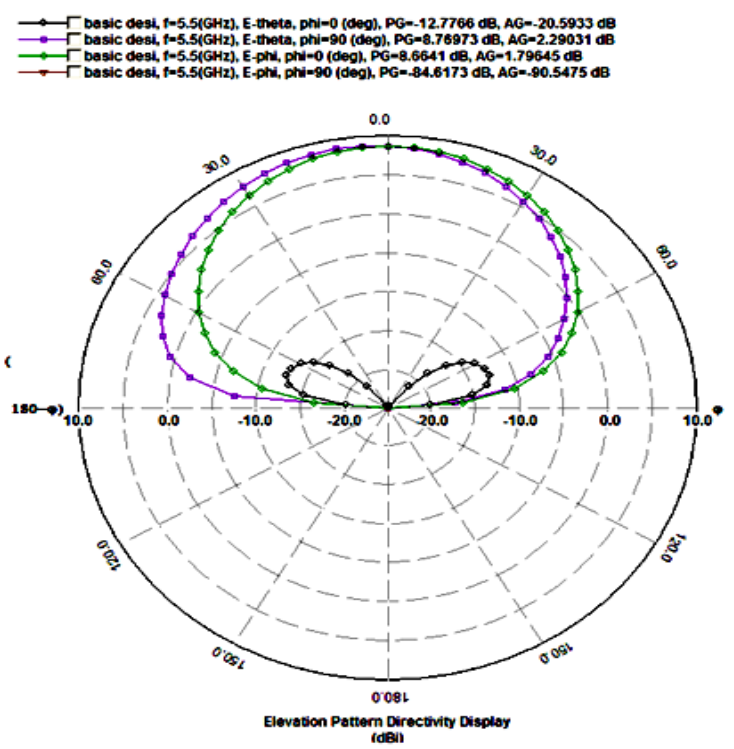

(c)
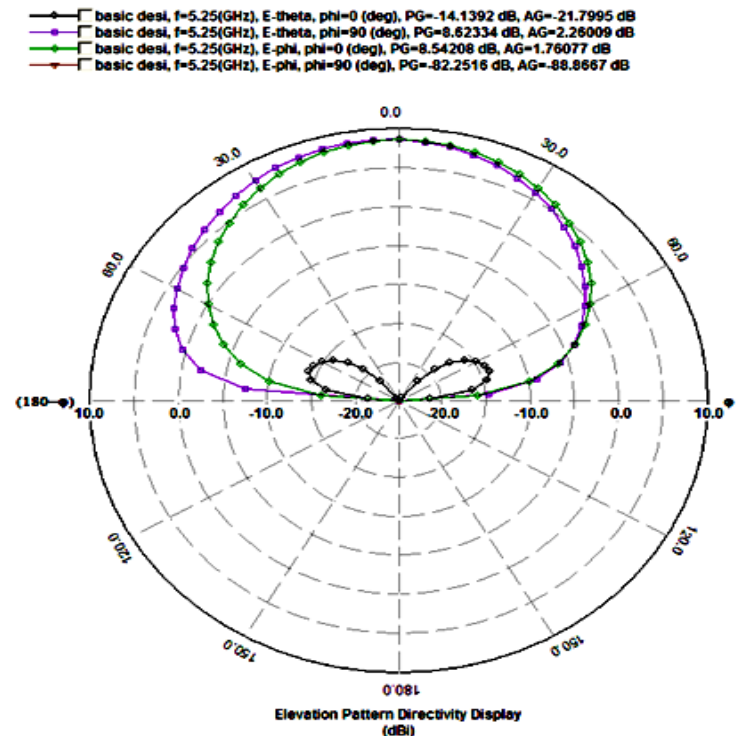

(b)
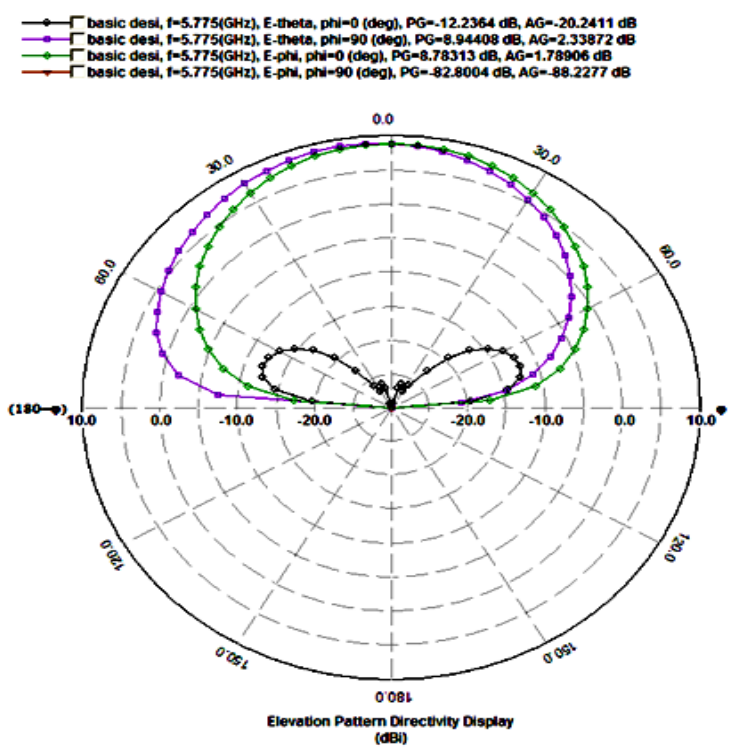

(d)

Fig 10: Radiation patterns at a) $5 \mathrm{GHz}$, b) $5.25 \mathrm{GHz}$, c) $5.5 \mathrm{GHz}$ and d) $5.775 \mathrm{GHz}$

In this work a single element, coaxial probe fed, single stacked, E shaped microstrip patch antenna has been designed and optimized for a frequency band of 4.9-5.825 GHz. The antenna showed satisfactory simulation results for all the high speed WLAN standards available throughout the world. The proposed antenna showed improvement in terms of bandwidth, return loss and size from any of the existing antenna in this frequency band. A parametric study has been done to understand the effect of various parameters on the resonant frequency, return loss, gain and bandwidth. An increase in bandwidth has been achieved by which now this single antenna can be used a transceiver throughout world for many WLAN standards including IEEE 802.11a, IEEE 802.11n and IEEE 802.11j. A reduction of antenna area has been achieved as our proposed antenna needs only $26 \times 19 \mathrm{~mm}^{2}$ area which is much smaller than the antennas found in literature review. The results of the parametric study is summarized in Table 1 which can be used as a reference in any future works in the field of E-shaped microstrip patches. In the future, additional band may be removed for more precise operation only in WLAN range. Fabrication of this antenna can be performed to observe real time performance of the antenna. Further improvement can be achieved by using arrays. Using multiple layer of substrate in stacked configuration can also improve return loss and bandwidth significantly. If successful, this can be produced commercially to be used in all WLAN applications throughout the globe. 
Table 1: Summary of Parametric Study

\begin{tabular}{|c|c|c|c|}
\hline & Decreasing & Parameters & Increasing \\
\hline Return loss & Increasing until $\mathrm{W}=24 \mathrm{~mm}$ & \multirow{3}{*}{$\begin{array}{c}\mathbf{W} \\
\text { (Original=34mm) } \\
\text { (Final=24mm) }\end{array}$} & Decreasing \\
\hline $\begin{array}{l}\text { Primary } \\
\text { Resonant } \\
\text { Frequency }\end{array}$ & Increasing & & Decreasing \\
\hline Bandwidth & Slightly Increasing & & Almost Similar \\
\hline Return loss & Increasing until $\mathrm{W} 1=5 \mathrm{~mm}$ & \multirow{3}{*}{$\begin{array}{c}\text { W1 } \\
\text { (Original=10mm) } \\
(\text { Final=5mm })\end{array}$} & Decreasing \\
\hline $\begin{array}{l}\text { Primary } \\
\text { Resonant } \\
\text { Frequency }\end{array}$ & Increasing & & Decreasing \\
\hline Bandwidth & Increasing until $\mathrm{W} 1=5 \mathrm{~mm}$ & & Decreasing \\
\hline Return loss & Decreasing & \multirow{3}{*}{$\begin{array}{c}\mathbf{L} \\
(\mathrm{L}=19 \mathrm{~mm})\end{array}$} & Decreasing \\
\hline $\begin{array}{l}\text { Primary } \\
\text { Resonant } \\
\text { Frequency }\end{array}$ & Increasing & & Decreasing \\
\hline Bandwidth & Almost Similar & & Almost Similar \\
\hline Return loss & Decreasing & \multirow{3}{*}{$\begin{array}{c}\text { L1 } \\
\text { (Original=13mm) } \\
(\text { Final=13.94mm) }\end{array}$} & $\begin{array}{l}\text { Almost Similar upto } \mathrm{L} 1=14 \mathrm{~mm} \\
\text { then decreasing }\end{array}$ \\
\hline $\begin{array}{l}\text { Primary } \\
\text { Resonant } \\
\text { Frequency }\end{array}$ & Increasing & & Decreasing \\
\hline Bandwidth & Almost Similar & & Almost Similar \\
\hline Return loss & Increasing abruptly & \multirow{3}{*}{$\begin{array}{c}\mathrm{W} 2 \\
(\mathrm{~W} 2=9 \mathrm{~mm})\end{array}$} & Decreasing Abruptly \\
\hline $\begin{array}{l}\text { Primary } \\
\text { Resonant } \\
\text { Frequency }\end{array}$ & Decreasing & & Increasing \\
\hline Bandwidth & Almost Similar & & Almost Similar \\
\hline Return loss & Increasing & \multirow{3}{*}{$\begin{array}{c}\text { Ls } \\
(\mathrm{Ls}=13.8 \mathrm{~mm})\end{array}$} & Decreasing \\
\hline $\begin{array}{l}\text { Primary } \\
\text { Resonant } \\
\text { Frequency }\end{array}$ & Decreasing & & Increasing \\
\hline Bandwidth & Decreasing & & Decreasing \\
\hline
\end{tabular}




\section{REFERENCES}

[1] Lee, K. F., et al., "Experimental and simulation studies of the coaxially fed U-slots rectangular patch antenna," IEEE Proc. Microw. Antenna Propagation, Vol. 144, No. 5, 354-358, October 1997.

[2] Chair, R., Mak, C. L., Lee, K. F., Luk, K. M. , Kishk, A. A., "Miniature Wide-Band Half U-Slot and Half EShaped Patch Antennas," IEEE Transactions on Antennas and Propagation, Vol. 53, No. 8, pp. 26452652, August 2005.

[3] Rafi, G. and L. Shafai, "Broadband micro-strip patch antenna with V-slot," IEE Proc. Microw. Antenna Propagation, Vol. 151, No. 5, 435-440, October 2004.

[4] M. Sanad, "Double C-patch antennas having different aperture shapes," in Proc. IEEE AP-S Symp., Newport Beach, CA, June 1995, pp. 2116-2119.

[5] Yang, F., X. X. Zhang, X. Ye, and Y. Rahmat-Samii, "Wide-band E-shaped patch antennas for wireless communications," IEEE Trans. Antennas Propagat., Vol. 49, No. 7, 1094-1100, July 2001.

[6] Ge, Y., K. P. Esselle, and T. S. Bird, "A compact Eshaped patch antenna with corrugated wings," IEEE Trans. Antennas Propagation, Vol. 54, No. 8, 24112413, Aug. 2006.

[7] $\mathrm{Yu}, \mathrm{A}$. and $\mathrm{X}$. X. Zhang, "A method to enhance the bandwidth of microstrip antennas using a modified Eshaped patch," Proceedings of Radio and Wireless Conference, 261-264, Aug. 10-13, 2003.
[8] Khidre, A., Lee, K. F., Yang, F., and Eisherbeni, A., "Wideband Circularly Polarized E-Shaped Patch Antenna for Wireless Applications", IEEE Antennas and Propagation Magazine, Vol. 52, No.5, October 2010. pp. 219-229.

[9] Sim, C. Y. D., J. S. Row, and Y. Y. Liou, "Experimental studies of a shorted triangular micro-strip antenna embedded with dual V-shaped slots," Journal of Electromagnetic Waves and Applications, Vol. 21, No. 1, 15-24, 2007.

[10] Kaizhong Zhan, Qinggong Quo, and Kama Huang, "A novel kind of Bluetooth and UWB antenna," 2010 International Conference on Microwave and Millimeter Wave Technology (ICMMT), pp. 1038 - 1041.

[11] Matin, M.A.; Ali, M.A.M.; "Design of broadband stacked E-shaped patch antenna," International Conference on Microwave and Millimeter Wave Technology (ICMMT 2008), vol.4, pp.1662-1663, 21-24 April 2008.

[12] Singh, A.; "Dual band E-shaped patch antenna (ESPA) for ultra wide band applications," Asia Pacific Microwave Conference (APMC 2009), pp.2770- 2773, 7-10 Dec. 2009

[13] D. K. Neog, S. S. Pattnaik, D. C. Panda, S. Devi, Malay Dutta and O. P. Bajpai, "New Expression for the resonance frequency of an E-shaped Microstrip Antenna," Wiley periodicals on Microwave and optical technology letters, Vol. 48, No. 8, pp.1561 -1563, August 2006 